\title{
Evaluation of firefighters' heat strain using heart rate during breaks at work
}

\author{
Siyeon Kim, Joo-Young Lee \\ From 15th International Conference on Environmental Ergonomics (ICEE XV) \\ Portsmouth, UK. 28 June - 3 July 2015
}

\section{Introduction}

Real-time monitoring of firefighters' heat strain during work has been attempted by recording deep body temperature and heart rate (HR). However, monitoring deep body temperature with HR during firefighting is cumbersome and inconvenient for firefighters. Furthermore, monitoring either deep body temperature or HR solely does not reflect full heat strain during firefighting while wearing personal protective clothing with self-contained breathing apparatus (SCBA). Because the capacity of SCBA is limited to 30 45 min, firefighters should take short breaks during firefighting to replace the SCBA. In the US, they provide guidelines to have firefighters take a minimum 10 min break after using a bottle of SCBA, and a minimum 20 min break after using two bottles of SCBA. However, it is more helpful to prevent heat-related illness and diseases of firefighters if we propose a necessary break time based on non-invasivelymonitored physiological response. The purpose of the present study was to investigate the possibility of HR as a heat strain index for firefighters during rest periods.

\section{Methods}

Twelve professional male firefighters participated in an experiment wearing firefighters' personal protective equipment $(15 \mathrm{~kg})$ with intermittent exercises at an air temperature of $32{ }^{\circ} \mathrm{C}$ and $43 \%$ relative humidity. Participants began each trial with a 10 min rest and performed two bouts of $15 \mathrm{~min}$ exercises on a treadmill at $5.5 \mathrm{~km}$. $\mathrm{hr}^{-1}\left(60 \% \mathrm{VO}_{2 \max }\right)$ that were separated by $10 \mathrm{~min}$ of seated rest. $H R$, rectal temperature $\left(\mathrm{T}_{\mathrm{re}}\right)$, and oxygen consumption were measured. $\mathrm{T}_{\text {re.break }}$ and $\Delta \mathrm{T}_{\text {re.break }}$ were defined as $T_{\text {re }}$ during rest periods and changes in $\mathrm{T}_{\mathrm{re}}$ during rest, respectively. Linear regression equations were derived between $\mathrm{HR}$ and $\mathrm{T}_{\mathrm{re}}$. Heart rate was expressed as absolute $\left(\mathrm{HR}_{\mathrm{absolute}} \mathrm{bpm}\right)$ and relative values $\left(\mathrm{HR}_{\text {relative, }} \% \mathrm{HR} \mathrm{R}_{\text {max }}\right)$.
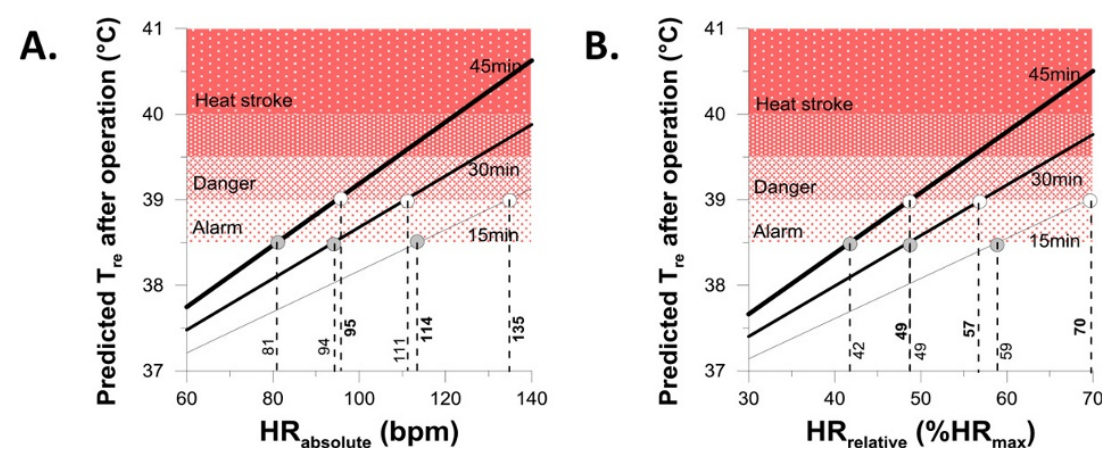

Figure 1 Reference values of heart rate to commence firefighting operations for $15 \mathrm{~min}, \mathbf{3 0} \mathrm{min}$, and $\mathbf{4 5} \mathrm{min}$. A: Absolute value of heart rate $(\mathrm{bpm}), \mathrm{B}$ : Relative value of $\mathrm{HR}(\% \mathrm{HR}$ max $)$.

\footnotetext{
* Correspondence: leex3140@snu.ac.kr

COM:FORT Laboratory, College of Human Ecology, Seoul National University, Seoul, Republic of Korea
} 


\section{Results}

During rest periods, significant regression equations were derived between $H R$ and $T_{\text {re; }}$ and between $H R$ and $\Delta T_{\text {re: }}$ :

$$
\begin{aligned}
& \mathrm{T}_{\text {re.break }}=0.035 \cdot \mathrm{HR}_{\text {relative }}+35.83\left(\mathrm{R}^{2}=0.722, P<0.05\right) \\
& \Delta \mathrm{T}_{\text {re.break }}=0.0008 \cdot \mathrm{HR}_{\text {relative }}-0.0066\left(\mathrm{R}^{2}=0.506, P<0.05\right) \\
& \mathrm{T}_{\mathrm{r}}(t)=0.035 \% H R_{\text {rest }}+35.830+\left(8 \times \% H R_{\text {rest }}+66\right) \cdot 10^{-4} \cdot \mathrm{t}\left(\mathrm{R}^{2}=0.708, P<0.05\right)
\end{aligned}
$$

By using equation 3, we calculated HR reference values which can identify when it is safe to continue $15 \mathrm{~min}$, $30 \mathrm{~min}$ or $45 \mathrm{~min}$ operations after breaks (Figure 1). For example, to continue a 15 min of operation after a break at work without any heat-related illness, $\mathrm{HR}$ during the break should be less than $70 \% \mathrm{HR}_{\max }\left(39^{\circ} \mathrm{C} \mathrm{T}_{\mathrm{re}}\right.$ predicted).

\section{Conclusion}

We confirmed the possibility of using a heart rate index during breaks at work to evaluate firefighters' heat strain. Using heart rate during breaks at work, we can determine whether to continue or stop firefighters' operations in hot environments. However, further studies are required to confirm the validity of using a heart rate index in various thermal environments and work intensities of firefighting to determine when it is safe to return to work.

Published: 14 September 2015

doi:10.1186/2046-7648-4-S1-A52

Cite this article as: Kim and Lee: Evaluation of firefighters' heat strain using heart rate during breaks at work. Extreme Physiology \& Medicine 2015 4(Suppl 1):A52.

Submit your next manuscript to BioMed Central and take full advantage of:

- Convenient online submission

- Thorough peer review

- No space constraints or color figure charges

- Immediate publication on acceptance

- Inclusion in PubMed, CAS, Scopus and Google Scholar

- Research which is freely available for redistribution

Submit your manuscript at www.biomedcentral.com/submit 